\title{
Immunogenicity and Immunodominance in Antibody Responses
}

\author{
Monique Vogel and Martin F. Bachmann
}

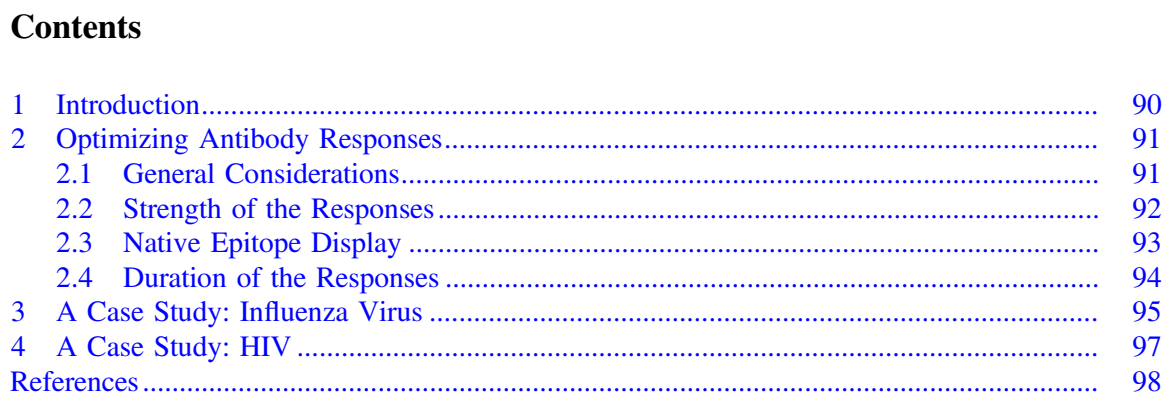

\begin{abstract}
A large number of vaccines exist that control many of the most important infectious diseases. Despite these successes, there remain many pathogens without effective prophylactic vaccines. Notwithstanding strong difference in the biology of these infectious agents, there exist common problems in vaccine design. Many infectious agents have highly variable surface antigens and/or unusually high antibody levels are required for protection. Such high variability may be addressed by using conserved epitopes and these are, however, usually difficult to display with the right conformation in an immunogenic fashion. Exceptionally high antibody titers may be achieved using life vectors or virus-like display of the epitopes. Hence, an important goal in modern vaccinology is to induce high antibody responses against fragile antigens.
\end{abstract}

M. Vogel · M. F. Bachmann ( $₫)$

Department of Rheumatology, Immunology and Allergology, University Hospital Bern,

Sahlihaus 2, CH-3010 Bern, Switzerland

e-mail: Martin.bachmann@me.com

M. Vogel

e-mail: monique.vogel@dbmr.unibe.ch

M. F. Bachmann

The Jenner Institute, University of Oxford, Oxford, UK

Current Topics in Microbiology and Immunology (2020) 428: 89-102

https://doi.org/10.1007/82_2019_160

(C) Springer Nature Switzerland AG 2019

Published Online: 28 March 2019 


\section{Introduction}

The most successful prophylactic vaccines are based on the induction of neutralizing antibodies. Indeed, almost all currently used vaccines have neutralizing antibodies as their primary protective mechanism. These vaccines profit from two important features of the pathogens they are designed to protect against: (1) low amounts of specific antibodies are usually sufficient for protection and (2) the epitopes recognized by neutralizing antibodies are well exposed and stable. Hence, the prototype antiviral vaccine consists of chemically inactivated viral particles and the prototype antibacterial vaccine is either a chemically inactivated toxin or bacterial carbohydrates coupled to a protein carrier. In many instances, such vaccines induce low levels of specific antibodies, which, however, suffice to protect against infection. Influenza virus may be a point in case, where an antiviral titer of 1:64 (measured by hemagglutination inhibition) is considered to be protective.

The most searched for vaccines are directed against two major types of pathogens, namely, the recently emerging ones and those where the induction of protective antibody levels is difficult (Table 1). The first class has prominent members such as Ebola, MERS, SARS, and emerging influenza strains. The difficulty in making vaccines against these pathogens are not because it would be technically challenging but rather because of the stringent timelines and the often low attack rates, which renders registration studies a difficult task. It is obvious that for a vaccine that usually needs $>10$ years of development, a virus-like SARS, which caused a dangerous outbreak but disappeared thereafter, is a formidably difficult target. Nevertheless, the recent success with the successful registration of an Ebola vaccine has shown that such problems can be solved in face of an infectious outbreak threatening large parts of the world.

This review will focus on vaccines against pathogens with demanding immunological properties and discuss some of the challenges and possible strategies to cope with them.

Table 1 The two main groups of pathogens with remaining difficulties for development of protective vaccines

\begin{tabular}{l|l|l}
\hline \multirow{2}{*}{} & \multicolumn{2}{|l}{ Two types of pathogens difficult to target } \\
\cline { 2 - 3 } & Complex Biology & Emerging Diseases \\
\hline Characteristics of & $\begin{array}{l}\text { Generation of neutralizing Ab } \\
\text { difficult }\end{array}$ & $\begin{array}{l}\text { Generation of neutralizing Ab } \\
\text { simple }\end{array}$ \\
& $\begin{array}{l}\text { High amounts of Ab needed } \\
\text { Ab may not be protective }\end{array}$ & $\begin{array}{l}\text { Low amounts of Ab needed } \\
\text { Ab alone protective }\end{array}$ \\
\hline Timelines & Not critical & Critical \\
\hline Examples & Tuberculosis, malaria, HIV & Ebola, MERS, Zika, SARS \\
\hline
\end{tabular}




\section{Optimizing Antibody Responses}

\subsection{General Considerations}

Two important factors have to be taken into consideration for antigen display. Namely, display of native, conformational epitopes with an ability to induce functionally relevant, protective antibodies as well as presenting epitopes in a maximally immunogenic fashion.

Viruses are well known for their ability to induce strong and long-lasting antibody response. The reasons and mechanism causing the strong immunogenicity of viruses have been elucidated in recent years and three key parameters have been identified (Bachmann and Jennings 2010; Jennings and Bachmann 2007): (1) the surface of most viruses is highly repetitive and exhibits an ordered and organized surface structure; (2) viruses are nanoparticles and exhibit the right size to freely reach B cell follicles via lymph in absence of cellular transport for interaction with B cells in a native form; and (3) they are able to trigger toll-like and other innate receptors and activate the complement cascade. This will enhance magnitude and duration of IgG responses as well as cause isotype switching to more protective subclasses.

Thus, viruses and viral immunology may serve as a paradigm for vaccine design and formulation. In general terms, novel vaccines against pathogens with complex immunology should display native epitopes in a highly repetitive fashion on a particulate scaffold, which should be linked to potent adjuvants such as TLR ligands. This will allow induction of immune responses of appropriate magnitude, quality, and specificity (Fig. 1a).

(a)

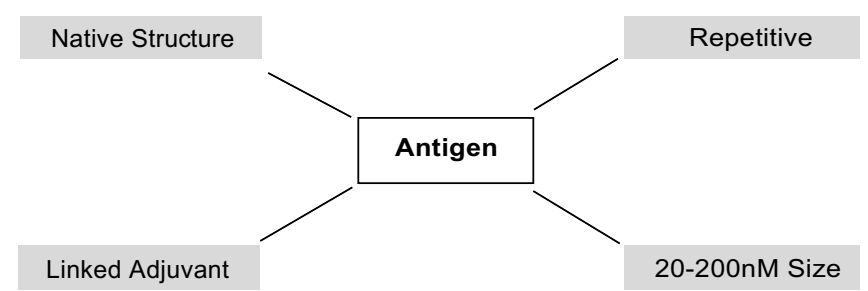

(b)

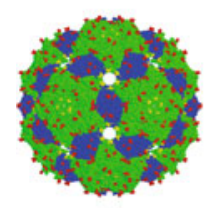

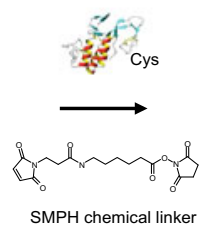

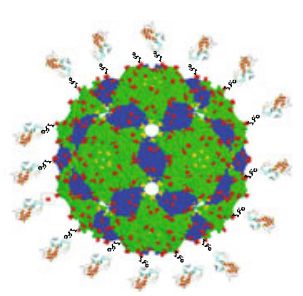

- Native Display

- Repetitive Display

- Size: $30 \mathrm{~nm}$

$\rightarrow$ Optimal for drainage

- VLPs loaded with RNA

$\rightarrow$ TLR $7 / 8$

Fig. 1 Four critical parameters for designing vaccines against complex antigens. a general outline of the four critical features. b outline of one specific solution for vaccine design. Antigens are displayed on RNA-loaded VLPs by means of chemical conjugation 
Virus-like particles (VLPs) represent an interesting vaccine design platform that is able to combine many of the elements above into a single system making them extremely potent inducers of neutralizing antibody responses. Indeed, during the last 30 years, vaccines based on VLPs have been the subject of extensive preclinical and clinical research. Several highly efficacious VLP-based vaccines for prevention of infection with hepatitis B or human papillomaviruses are today marketed for human use and a large number of VLP-based vaccines are under development, targeting diseases as different as influenza virus (Lopez-Macias et al. 2011), malaria (Aponte et al. 2007), or Alzheimer`s disease (Winblad et al. 2012). VLPs may be used to induce antibodies against the VLP itself or antigens displayed on them (Fig. 1b).

\subsection{Strength of the Responses}

Soluble antigens are usually very poorly immunogenic unless formulated in appropriate adjuvants and even then immunogenicity may remain too low for efficacy. It is therefore of interest to display epitopes in an inherently more immunogenic fashion. One possibility is to directly link the antigen to a molecular adjuvant, such as bacterial DNA, an option that will be discussed in the next section. Multimeric display is an additional powerful way to enhance antibody responses. Viral particles usually exhibit highly repetitive and quasi-crystalline surfaces and are known for their ability to induce rapid and strong antibody responses (Bachmann and Zinkernagel 1997). The explanation for the high immunogenicity of repetitive surfaces is as follows. Most viral genomes, in particular RNA viruses, are small and encode relatively few gene products which limit the number of available structural proteins. Therefore, viruses are forced to use multiple copies of a few proteins to assemble their envelopes and cores. As a consequence, viral surfaces consist of ordered and repeated subunits forming a densely packed quasi-crystalline and organized surface. Coevolution of viruses and hosts has resulted in an adaptive immune system rapidly detecting, discriminating, and responding to these repeated and ordered structures found on viral surfaces (Bachmann and Zinkernagel 1996). Hence, antigen organization and repetitiveness is a geometric pathogen-associated molecular pattern. At the cellular level, organized epitopes on the viral surface cross-link specific B cell receptors (BCR) on the surface of B cells. Cross-linking of the BCR resulting in stabilizing BCR-signaling micro-domains constitutes a strong activation signal for B cells and can cause prompt T-independent IgM response (Bachmann et al. 1995; Thyagarajan et al. 2003). Viral proteins expressed in an ordered and repetitive fashion are considerably more immunogenic than in soluble form and can even overcome B cell tolerance (Bachmann et al. 1993; Justewicz et al. 1995; Schodel et al. 1993). The optimal spacing of epitopes for activation of B cells has been analyzed using haptenated polymers and the immunon was defined as 20-25 epitopes spaced by 5-10 nm leading to optimal geometric characteristics for B cell activation (Dintzis et al. 1982). Immunogenic epitopes displayed on viruses and VLPs have similar numbers and distance (Jegerlehner et al. 2002). 
There are multiple ways to render antigens highly organized. Some viral proteins spontaneously assemble into VLPs upon expression, constituting a simple way to render the proteins highly repetitive. Indeed, the successful vaccines against hepatitis B and human papillomavirus (HPV) are examples of proteins spontaneously assembling into VLPs. VLPs may be used as scaffolds for antigen displays and genetic fusion of epitopes to the surface of VLPs is an elegant way to give the displayed antigens a "viral fingerprint" by rendering them highly organized (Rhee and Barouch 2009). Although often successful, the genetic fusion approach whereby an antigen is genetically linked to a VLP may limit the size and nature of the epitopes display as complex epitopes often are not compatible with correct assembly of the VLPs. As an alternative, we have developed a method of chemical conjugation, whereby VLPs and antigens are expressed separately and brought together by means of chemical cross-linking. Clinical proof of concept has been achieved for a number of vaccine candidates, including a vaccine against hypertension (Tissot et al. 2008), smoking (Cornuz et al. 2008), allergy (Kundig et al. 2006), and influenza virus (Low et al. 2014). A vaccine against Alzheimer's disease based on a peptide displayed on VLPs is currently undergoing late-stage clinical development (Winblad et al. 2012). An additional method is the SpyCatcher system, whereby autocatalytic peptides are used that bind to each other and undergo covalent linkage (Zakeri et al. 2012; Thrane et al. 2016; Brune et al. 2016). This technology has proven highly efficient at least at lab scale.

There are a number of additional platforms that allow rendering antigens of choice multivalent. Linking antigens to transferrin has been used to render the hemagglutinin of influenza virus highly immunogenic (Santiago et al. 2012). Fusion of antigens to the coiled structure of complement component $3 \mathrm{~d}$ (C3d) is another way to render antigens that are least pentavalent and to enhance the immune response to various foreign and self-antigens (Toapanta and Ross 2006).

Size may also be important for induction of potent B cell responses. Small particles with the dimensions of viruses and VLPs efficiently drain or diffuse to lymph nodes from the site of injection as they can directly enter lymph vessels without the need of cellular transport. Thus, VLPs can enter secondary lymphoid organs and interact directly with B cells to trigger antibody responses. In contrast, larger particles with size $>200-500 \mathrm{~nm}$ cannot enter the lymphatic system and need to be transported by dendritic cells (Manolova et al. 2008). The fact that active cellular transport by dendritic cells is not required to deliver particles with viral size to $\mathrm{B}$ cells means that conformation-dependent epitopes can be presented in a non-processed form and optimal B cell responses may be induced.

\subsection{Native Epitope Display}

As discussed above, most currently used vaccines are against pathogens for which induction of neutralizing and protective antibodies is relatively simple. As an example, poliovirus displays neutralizing epitopes in a rigid and stable form and 
attenuated as well as inactivated viruses therefore readily induce neutralizing antibodies. As discussed previously (Bachmann and Zinkernagel 1996), this probably reflects the situation that most viruses, in particular cytolytic viruses, cannot establish a stable long-term relationship with the human host in the absence of rapid induction of neutralizing antibodies protecting the host from lethal infection. This is different for viruses such as HIV, where epitopes with the ability to induce antibodies neutralizing a large number of different viral strains are very unstable and only occur transiently during cellular infection (Karlsson Hedestam et al. 2008). Furthermore, other protective epitopes may be shielded away by, e.g., carbohydrates (e.g., HIV) or protein domains as, e.g., the malaria MSP-1 protein (Guevara Patino et al. 1997)) or the influenza HA stem (Justewicz et al. 1995). Display of such fragile or naturally not exposed epitopes requires careful design going much further than simply using linear peptides as epitope mimic [see, e.g., (Timmerman et al. 2009)]. In addition, testing of large numbers of differently truncated proteins or protein domains may be required to find a version exposing naturally hidden epitopes in a conformationally appropriate way. In both cases, trial and error remains the dominant path forward. Even for a small molecule like nicotine, a large number of different molecules may need to be tested for induction of optimal antibodies (Pryde et al. 2013). In addition, one should keep in mind that binding to a synthetic epitope by a neutralizing antibody does not imply that the same epitope is able to induce such neutralizing antibodies. Specifically, a specific neutralizing antibody may induce a subtle conformational change in the synthetic peptide mimic, which allows optimal binding. Using this same epitope for vaccination may therefore result in a wide range of different antibody specificities with only a small fraction exhibiting the desired neutralizing activity. For this reason, not many vaccine candidates based on such epitopes have successfully entered clinical development.

An additional parameter to consider is the adjuvants used. Alum has, e.g., the tendency to denature fragile antigens resulting in enhanced ELISA titers which not necessarily correlate with enhanced neutralizing antibody responses (Skibinski et al. 2013). We have recently compared Alum to microcrystalline tyrosine (MCT) and found that antibody responses were higher with Alum if assessed by ELISA but the protective capacity of the induced antibodies was higher if MCT was used as the adjuvant (Cabral-Miranda et al. 2017). Native display of antigens on immunogenic carriers, which do not need an adjuvant, may also be an attractive technology to induce potent cellular and humoral responses.

\subsection{Duration of the Responses}

The innate immune system has been known for a long time to enhance adaptive immunity. Indeed, both $\mathrm{B}$ and $\mathrm{T}$ cell responses profit from co-engagement of the innate immune system. B cell responses may be influenced directly via B-cell-intrinsic TLR signaling or indirectly via induction of $\mathrm{T}_{\mathrm{FH}}$ cells by activated 
dendritic cells (Hou et al. 2011; Jegerlehner et al. 2007). Even Alum, an adjuvant not necessarily associated with specific activation of the innate immune system, has been shown to activate the inflammasome linking Alum to the production of IL-1 (Eisenbarth et al. 2008). The importance of this activation for the adjuvants effect remains, however, controversial (Spreafico et al. 2010). Direct stimulation of B cells by specific delivery of TLR ligands is probably the most potent way to employ the adjuvants. Indeed, conjugation of $\mathrm{CpGs}$ to proteins has been shown to be more potent than simple mixing (Bourquin et al. 2008; Eckl-Dorna and Batista 2009; Storni et al. 2004). Furthermore, packaging of RNA or CpGs into viral particles induces potent IgG2a as well as systemic IgA responses in the mouse (Bessa et al. 2008; Jegerlehner et al. 2007). Such particles also induce potent mucosal responses if applied intranasally. Hence, conjugation or packaging of immunostimulatory sequences seems the most potent way to employing them as adjuvants.

Repetitive and organized structures harness the innate immune system in a second way (Bachmann and Jennings 2010). This is due to the fact that repetitive structures are preferentially recognized by components of the complement system and natural antibodies. This results in enhanced phagocytosis and antigen processing, increasing induction of T cell help (Fanger et al. 1996; Matsushita and Fujita 2001). As induction of GC reactions, memory B cells and long-lived plasma cells are Th cell dependent, and this may result in overall increased antibody responses (Bachmann and Zinkernagel 1997). An additional and equally important consequence of binding natural IgM antibodies and complement has enhanced deposition of repetitive structures such as viral particles on FDCs in germinal centers. Indeed, B cells have been shown to bind viral particles to their surface complement receptors CD21 and transport them to FDCs within B cell follicles, driving enhanced GC reactions (Link et al. 2012; Phan et al. 2007). Repetitive antigens may also be transported bound to low-affinity BCRs on B cells for deposition on FDCs (Bessa et al. 2012). In addition, CD21 engagement by complement components bound to repetitive surfaces enhances expression of the plasma cell-specific transcription factors blimp and XBP-1, enabling generation of long-lived plasma cells and prolonging IgG responses (Gatto et al. 2005). Furthermore, complement bound to VLPs reduces the threshold required for B cell activation (Jegerlehner et al. 2002).

\section{A Case Study: Influenza Virus}

Influenza viruses are RNA viruses and are divided into three different types, namely, influenza $\mathrm{A}, \mathrm{B}$, and $\mathrm{C}$ viruses. Types $\mathrm{B}$ and $\mathrm{C}$ are almost exclusively found in humans, whereas influenza A virus circulates in a large variety of warm-blooded animals including birds, pigs, and humans. Influenza A virus is further classified by the antigenic characterization of two major surface glycoproteins, hemagglutinin (HA), and neuraminidase (NA) (Krammer et al. 2015). HA is a lectin responsible for the binding of the virus to target cells via sialic acids, whereas NA is involved in 
the delivery of the virus from the cells by cleaving sialic acid from the infected cells to allow release of infectious particles. These two proteins are used to classify influenza virus into different subtypes. Up to now 18 different HA and 9 different NA have been identified and the first three HA, H1, H2, H3 are commonly found in humans. HA is a homotrimer consisting of a globular head, HA1 that contains the major antigenic sites, and a stalk/stem region, HA2, that anchors the protein in the virus membrane and contains the viral fusion machinery. While HA1 is highly variable, HA2 is very well conserved. Since HA is the protein involved in the entry process, it is also the primary target for neutralizing antibodies elicited by conventional influenza vaccines. Most of these HA-specific neutralizing antibodies are, however, strain specific because they bind to HA1 whose antigenic sites are subjected to antigenic drift in circulating strains. This antigenic drift makes it necessary to generate new vaccines almost every year and the duration of protection is short. Furthermore, these vaccines do not protect against novel pandemic strains as once a novel pandemic virus is identified it takes several months to develop the new vaccine and some more weeks are required for induction of protective immune responses. Induction of long-term protective immunity not affected by antigenic drift is therefore a major goal in vaccine development. Displaying HA1 on VLPs has proven successful to induce protective antibody responses in mice (Jegerlehner et al. 2013) and humans (Low et al. 2014). This type of vaccine, however, suffers from the same susceptibility to antigenic drift as the classical vaccines. A vaccine targeting either the stalk domain (HA2) or the extracellular domain of the M2 ion channel protein, which is also highly conserved, would be promising targets to develop a universal influenza vaccine and overcome the conserved drift of seasonal influenza virus vaccines. Recent studies have demonstrated the feasibility of using stalk domain-based vaccines. Antibodies against stalk domain have been shown to bind to either group 1 or group 2 hemagglutinins (Sui et al. 2009), both (Corti et al. (2011; Ekiert et al. 2009; Wyrzucki et al. 2015), or even viruses for both the A and B genera (Dreyfus et al. 2012). Using recombinant DNA technology, HA constructs devoid of the highly immunogenic head domain were expressed on the cell surfaces. Co-expression of an HIV Gag-based construct with headless HA constructs lead to the production of chimeric headless HLA virus-like particles (VLPs) (Smith et al. 2013). Immunization of mice with these headless HA provided protection with moderate body weight loss against a lethal homologous viral challenge. Moreover, HA headless VLP immune sera showed reactivity to heterologous strains suggesting that vaccination with headless HA might induce protection against different influenza strains. Another study using chimeric HA constructs showed that by repeated immunization of mice, a broad protection against a variety of influenza virus strains could be elicited. However, up to now no vaccines have been developed that are able to induce protective anti-stalk antibodies regardless of HA subtypes. The extracellular domain of M2 is a poorly immunogenic and different approaches were tested to link M2 to carrier molecules or/and to use potent adjuvants to increase immunogenicity (Kang et al. 2012; Song et al. 2011). In particular, a virus-like particle (VLP)-based vaccine targeting M2 has been described to protect mice from lethal influenza infection (Jegerlehner et al. 
2004). Further studies analyzing M2-specfic antibodies showed that in contrast to conventional neutralizing antiviral antibodies, the M2 antibodies rely on their Fc part that binds to $\mathrm{Fc}$ receptor and to complement to be protective. Induction of potent IgG subclasses, such as IgG2a in the mouse, is therefore critical for this type of vaccine (Schmitz et al. 2012). Further studies investigating the protective potential of M2-specific antibodies in humans are, however, needed to evaluate the potential efficacy of this candidate antigen as universal vaccine.

\section{A Case Study: HIV}

The trimeric envelope glycoprotein of HIV is a complex protein that is highly glycosylated. The protein is cleaved from a $160 \mathrm{kD}$ precursor protein into gp41 and gp120 which exists as a trimer. This trimer is, however, rather unstable if expressed recombinantly. Furthermore, the trimeric form of gp120/gp41 can adopt different conformational states (conformers), which may induce different levels of neutralizing antibodies. Chemical stabilization of individual conformers may allow focusing of the response to broadly neutralizing antibodies (Schiffner et al. 2016).

There are three types of gp120-specific antibodies, namely, binding but not neutralizing antibodies, strain-specific neutralizing antibodies, and broadly neutralizing antibodies. Non-neutralizing antibodies recognize epitopes primarily exposed on non-native gp120. This class of antibodies is very abundant, as the gp120 trimer is inherently unstable. The strain-specific antibodies recognize epitopes on the native trimer (Burton and Mascola 2015), and these epitopes are, however, very variable and show great sequence variability. As these epitopes are usually well exposed, strain-specific neutralizing antibodies are also abundant. The broadly neutralizing antibodies also recognize epitopes on the native trimer (Burton and Mascola 2015), which are usually buried within a sea of variability and often not well accessible. The epitopes recognized by these most potent antibodies may be categorized into four classes: the CD4-binding site, two additional sites on the gp120, and a single site on gp41 (Sattentau 2014). It is the goal of all HIV vaccine strategies to induce such broadly neutralizing antibodies.

These features of HIV-GP pose a whole array of problems. First, the carbohydrates shield the protein effectively from the induction of neutralizing antibodies and serve as "dummy" antigens, distracting the immune system and preventing induction of more protective antibodies. Removal of glycosylation sites on proteins designed for vaccination may overcome this problem at least in part. Cleavage of the mature GP160 into GP41 and GP120 results in an unstable protein which readily falls apart. It has recently been shown that the complex can be stabilized by linking the gp41 and gp120 proteins by a disulphide bond (Sanders et al. 2013), resulting in the induction of more broadly neutralizing antibodies upon immunization with these modified trimers. The most difficult feature of the glycoprotein is the various conformational states the trimer may adopt. Attempts to stabilize the closed structure using chemical cross-linkers look promising but still does not 
easily allow induction of broadly neutralizing antibodies (Schiffner et al. 2016). An additional hurdle for induction of strong neutralizing antibody responses is the similarity of two important neutralizing epitopes with self-molecules, which renders induction of antibody responses difficult due to B cell tolerance (Yang et al. 2013).

Display of functional gp41/gp120 spikes displaying broadly neutralizing epitopes in an immunogenic manner is therefore the goal of current vaccine strategies. Display of separately expressed and stabilized trimers on VLPs by means of, e.g., chemical conjugation may be one way to achieve this goal. As highly repetitive arrays of antigens may overcome B cell tolerance (Bachmann et al. 1993), and this may additionally solve the issue with B cell repertoire tolerized by the cross-reactive self-antigens (Schiller and Chackerian 2014). Alternatively, the stabilized spikes may be formulated in an adjuvant that enhances immune responses without impairing the structure of the fragile epitopes.

Hence, designing an immunogen that displays epitopes of HIV-GP that allow induction of broadly neutralizing antibodies remains a formidable task but appears more feasible now than a few years ago.

\section{References}

Aponte JJ, Aide P, Renom M, Mandomando I, Bassat Q, Sacarlal J, Manaca MN, Lafuente S, Barbosa A, Leach A, Lievens M, Vekemans J, Sigauque B, Dubois MC, Demoitie MA, Sillman M, Savarese B, Mcneil JG, Macete E, Ballou WR, Cohen J, Alonso PL (2007) Safety of the RTS, S/ AS02D candidate malaria vaccine in infants living in a highly endemic area of Mozambique: a double blind randomised controlled phase I/IIb trial. Lancet 370(9598):1543-1551

Bachmann MF, Hengartner H, Zinkernagel RM (1995) T helper cell-independent neutralizing B cell response against vesicular stomatitis virus: role of antigen patterns in B cell induction? Eur J Immunol 25(12):3445-3451

Bachmann MF, Jennings GT (2010) Vaccine delivery: a matter of size, geometry, kinetics and molecular patterns. Nat Rev Immunol 10(11):787-796

Bachmann MF, Rohrer UH, Kundig TM, Burki K, Hengartner H, Zinkernagel RM (1993) The influence of antigen organization on B cell responsiveness. Science 262(5138):1448-1451

Bachmann MF, Zinkernagel RM (1996) The influence of virus structure on antibody responses and virus serotype formation. Immunol Today 17(12):553-558

Bachmann MF, Zinkernagel RM (1997) Neutralizing antiviral B cell responses. Annu Rev Immunol 15:235-270

Bessa J, Schmitz N, Hinton HJ, Schwarz K, Jegerlehner A, Bachmann MF (2008) Efficient induction of mucosal and systemic immune responses by virus-like particles administered intranasally: implications for vaccine design. Eur J Immunol 38(1):114-126

Bessa J, Zabel F, Link A, Jegerlehner A, Hinton HJ, Schmitz N, Bauer M, Kündig TM, Saudan P, Bachmann MF (2012) Low-affinity B cells transport viral particles from the lung to the spleen to initiate antibody responses. Proc Natl Acad Sci U S A. 109(50):20566-20571

Bourquin C, Anz D, Zwiorek K, Lanz AL, Fuchs S, Weigel S, Wurzenberger C, Von Der Borch P, Golic M, Moder S, Winter G, Coester C, Endres S (2008) Targeting CpG oligonucleotides to the lymph node by nanoparticles elicits efficient antitumoral immunity. J Immunol 181 (5):2990-2998

Brune KD, Leneghan DB, Brian IJ, Ishizuka AS, Bachmann MF, Draper SJ, Biswas S, Howarth M (2016) Sci Rep 19(6):19234 
Burton DR, Mascola JR (2015) Antibody responses to envelope glycoproteins in HIV-1 infection. Nat Immunol 16(6):571-576

Cabral-Miranda G, Heath MD, Gomes AC, Mohsen MO, Montoya-Diaz E, Salman AM, Atcheson E, Skinner MA, Kramer MF, Reyes-Sandoval A, Bachmann M (2017) Microcrystalline Tyrosine $\left(\mathrm{MCT}^{\circledR}\right)$ : a depot adjuvant in licensed allergy immunotherapy offers new opportunities in malaria. Vaccine 5(4)

Cornuz J, Zwahlen S, Jungi WF, Osterwalder J, Klingler K, Van Melle G, Bangala Y, Guessous I, Muller P, Willers J, Maurer P, Bachmann MF, Cerny T (2008) A vaccine against nicotine for smoking cessation: a randomized controlled trial. PLoS ONE 3(6):e2547

Corti D, Voss J, Gamblin SJ, Codoni G, Macagno A et al (2011) A neutralizing antibody selected from plasma cells that binds to group 1 and group 2 influenza a hemagglutinins. Science 333 (6044):850-56. https://doi.org/10.1126/science.1205669

Dintzis RZ, Vogelstein B, Dintzis HM (1982) Specific cellular stimulation in the primary immune response: experimental test of a quantized model. Proc Natl Acad Sci U S A 79(3):884-888

Dreyfus C, Laursen NS, Kwaks T, Zuijdgeest D, Khayat R et al (2012) Highly conserved protective epitopes on influenza B viruses. Science 337(6100):1343-48. https://doi.org/10. $1126 /$ science. 1222908

Eckl-Dorna J, Batista FD (2009) BCR-mediated uptake of antigen linked to TLR9 ligand stimulates B-cell proliferation and antigen-specific plasma cell formation. Blood 113 (17):3969-3977

Eisenbarth SC, Colegio OR, O'connor W, Sutterwala FS, Flavell RA (2008) Crucial role for the Nalp3 inflammasome in the immunostimulatory properties of aluminium adjuvants. Nature 453 (7198):1122-6

Ekiert, DC, Bhabha G, Elsliger MA, Friesen RHE, Jongeneelen M, others (2009) Antibody Recognition of a Highly Conserved Influenza Virus Epitope. Science, 324.5924:246-51. http:// dx.doi.org/10.1126/science.1171491

Fanger NA, Wardwell K, Shen L, Tedder TF, Guyre PM (1996) Type I (CD64) and type II (CD32) Fc gamma receptor-mediated phagocytosis by human blood dendritic cells. J Immunol 157 (2):541-548

Gatto D, Pfister T, Jegerlehner A, Martin SW, Kopf M, Bachmann MF (2005) Complement receptors regulate differentiation of bone marrow plasma cell precursors expressing transcription factors Blimp-1 and XBP-1. J Exp Med 201(6):993-1005

Guevara Patino JA, Holder AA, Mcbride JS, Blackman MJ (1997) Antibodies that inhibit malaria merozoite surface protein-1 processing and erythrocyte invasion are blocked by naturally acquired human antibodies. J Exp Med 186(10):1689-1699

Hou B, Saudan P, Ott G, Wheeler ML, Ji M, Kuzmich L, Lee LM, Coffman RL, Bachmann MF, Defranco AL (2011) Selective utilization of Toll-like receptor and MyD88 signaling in B cells for enhancement of the antiviral germinal center response. Immunity 34(3):375-384

Jegerlehner A, Maurer P, Bessa J, Hinton HJ, Kopf M, Bachmann MF (2007) TLR9 signaling in B cells determines class switch recombination to IgG2a. J Immunol 178(4):2415-2420

Jegerlehner A, Schmitz N, Storni T, Bachmann MF (2004) Influenza A vaccine based on the extracellular domain of M2: weak protection mediated via antibody-dependent NK cell activity. J Immunol 172(9):5598-5605

Jegerlehner A, Storni T, Lipowsky G, Schmid M, Pumpens P, Bachmann MF (2002) Regulation of IgG antibody responses by epitope density and CD21-mediated costimulation. Eur J Immunol 32(11):3305-3314

Jegerlehner A, Zabel F, Langer A, Dietmeier K, Jennings GT, Saudan P, Bachmann MF (2013) Bacterially produced recombinant influenza vaccines based on virus-like particles. PLoS ONE 8(11):e78947

Jennings GT, Bachmann MF (2007) Designing recombinant vaccines with viral properties: a rational approach to more effective vaccines. Curr Mol Med 7(2):143-155

Justewicz DM, Doherty PC, Webster RG (1995) The B-cell response in lymphoid tissue of mice immunized with various antigenic forms of the influenza virus hemagglutinin. J Virol 69 (9):5414-5421 
Kang SM, Kim MC, Compans RW (2012) Virus-like particles as universal influenza vaccines. Expert Rev Vaccines 11(8):995-1007

Karlsson Hedestam GB, Fouchier RA, Phogat S, Burton DR, Sodroski J, Wyatt RT (2008) The challenges of eliciting neutralizing antibodies to HIV-1 and to influenza virus. Nat Rev Microbiol 6(2):143-155

Krammer F, Palese P, Steel J (2015) Advances in universal influenza virus vaccine design and antibody mediated therapies based on conserved regions of the hemagglutinin. Curr Top Microbiol Immunol 386:301-321

Kundig TM, Senti G, Schnetzler G, Wolf C, Prinz Vavricka BM, Fulurija A, Hennecke F, Sladko K, Jennings GT, Bachmann MF (2006) Der p 1 peptide on virus-like particles is safe and highly immunogenic in healthy adults. J Allergy Clin Immunol 117(6):1470-1476

Link A, Zabel F, Schnetzler Y, Titz A, Brombacher F, Bachmann MF (2012) Innate immunity mediates follicular transport of particulate but not soluble protein antigen. J Immunol 188 (8):3724-3733

Lopez-Macias C, Ferat-Osorio E, Tenorio-Calvo A, Isibasi A, Talavera J, Arteaga-Ruiz O, Arriaga-Pizano L, Hickman SP, Allende M, Lenhard K, Pincus S, Connolly K, Raghunandan R, Smith G, Glenn G (2011) Safety and immunogenicity of a virus-like particle pandemic influenza A (H1N1) 2009 vaccine in a blinded, randomized, placebo-controlled trial of adults in Mexico. Vaccine 29(44):7826-7834

Low JG, Lee LS, Ooi EE, Ethirajulu K, Yeo P, Matter A, Connolly JE, Skibinski DA, Saudan P, Bachmann M, Hanson BJ, Lu Q, Maurer-Stroh S, Lim S, Novotny-Diermayr V (2014) Safety and immunogenicity of a virus-like particle pandemic influenza A (H1N1) 2009 vaccine: results from a double-blinded, randomized Phase I clinical trial in healthy Asian volunteers. Vaccine 32(39):5041-5048

Manolova V, Flace A, Bauer M, Schwarz K, Saudan P, Bachmann MF (2008) Nanoparticles target distinct dendritic cell populations according to their size. Eur J Immunol 38(5):1404-1413

Matsushita M, Fujita T (2001) Ficolins and the lectin complement pathway. Immunol Rev 180:78-85

Phan TG, Grigorova I, Okada T, Cyster JG (2007) Subcapsular encounter and complementdependent transport of immune complexes by lymph node B cells. Nat Immunol 8(9): 992-1000

Pryde DC, Jones LH, Gervais DP, Stead DR, Blakemore DC, Selby MD, Brown AD, Coe JW, Badland M, Beal DM, Glen R, Wharton Y, Miller GJ, White P, Zhang N, Benoit M, Robertson K, Merson JR, Davis HL, Mccluskie MJ (2013) Selection of a novel anti-nicotine vaccine: influence of antigen design on antibody function in mice. PLoS ONE 8(10):e76557

Rhee EG, Barouch DH (2009) Translational mini-review series on vaccines for HIV: harnessing innate immunity for HIV vaccine development. Clin Exp Immunol 157(2):174-180

Sanders RW, Derking R, Cupo A, Julien J, Yasmeen A, De Val N, Kim HJ, Blattner C, De La Pena AT, Korzun J, Gobalek M, De Los Reyes K, Ketas T, Van Gils M, King C, Wilson I, Ward AB, Klasse P, Moore JP (2013) A next generation cleaved, soluble HIV-1 Env trimer, BG505 SOSIp.664 gp140, expresses multiple epitopes for broadly neutralizing but non-neutralizing antibodies. PLos Pathog 9(9)(e1003618)

Santiago FW, Lambert Emo K, Fitzgerald T, Treanor JJ, Topham DJ (2012) Antigenic and immunogenic properties of recombinant hemagglutinin proteins from H1N1 A/Brisbane/59/07 and $\mathrm{B} /$ Florida/04/06 when produced in various protein expression systems. Vaccine 30 (31):4606-4616

Sattentau QJ (2014) Immunogen design to focus the B-cell repertoire. Curr Opin HIV AIDS 9 (3):217-223

Schiffner T, De Val N, Russell RA, De Taeye SW, De La Pena AT, Ozorowski G, Kim HJ, Nieusma T, Brod F, Cupo A, Sanders RW, Moore JP, Ward AB, Sattentau QJ (2016) Chemical cross-linking stabilizes native-like HIV-1 envelope glycoprotein trimer antigens. J Virol 90 (2):813-828

Schiller J, Chackerian B (2014) Why HIV virions have low numbers of envelope spikes: implications for vaccine development. PLos Pathog 10(8)(e1004254) 
Schmitz N, Beerli RR, Bauer M, Jegerlehner A, Dietmeier K, Maudrich M, Pumpens P, Saudan P, Bachmann MF (2012) Universal vaccine against influenza virus: linking TLR signaling to anti-viral protection. Eur J Immunol 42(4):863-869

Schodel F, Peterson D, Zheng J, Jones JE, Hughes JL, Milich DR (1993) Structure of hepatitis B virus core and e-antigen. A single precore amino acid prevents nucleocapsid assembly. J Biol Chem 268(2):1332-7

Skibinski DA, Hanson BJ, Lin Y, Von Messling V, Jegerlehner A, Tee JB, De Chye H, Wong SK, $\mathrm{Ng}$ AA, Lee HY, Au B, Lee BT, Santoso L, Poidinger M, Fairhurst AM, Matter A, Bachmann MF, Saudan P, Connolly JE (2013) Enhanced neutralizing antibody titers and Th1 polarization from a novel Escherichia coli derived pandemic influenza vaccine. PLoS ONE 8 (10):e76571

Smith GE, Flyer DC, Raghunandan R, Liu Y, Wei Z, Wu Y, Kpamegan E, Courbron D, Fries LF 3rd, Glenn GM (2013) Development of influenza H7N9 virus like particle (VLP) vaccine: homologous A/Anhui/1/2013 (H7N9) protection and heterologous A/chicken/Jalisco/CPA1/ 2012 (H7N3) cross-protection in vaccinated mice challenged with H7N9 virus. Vaccine 31 (40):4305-4313

Song JM, Van Rooijen N, Bozja J, Compans RW, Kang SM (2011) Vaccination inducing broad and improved cross protection against multiple subtypes of influenza A virus. Proc Natl Acad Sci U S A 108(2):757-761

Spreafico R, Ricciardi-Castagnoli P, Mortellaro A (2010) The controversial relationship between NLRP3, alum, danger signals and the next-generation adjuvants. Eur J Immunol 40(3):638642

Storni T, Ruedl C, Schwarz K, Schwendener RA, Renner WA, Bachmann MF (2004) Nonmethylated CG motifs packaged into virus-like particles induce protective cytotoxic $\mathrm{T}$ cell responses in the absence of systemic side effects. J Immunol 172(3):1777-1785

Sui J, Hwang WC, Perez S, Wei G, Aird D, Chen LM, Santelli E, Stec B, Cadwell G, Ali M, Wan H, Murakami A, Yammanuru A, Han T, Cox NJ, Bankston LA, Donis RO, Liddington RC, Marasco WA (2009) Structural and functional bases for broad-spectrum neutralization of avian and human influenza A viruses. Nat Struct Mol Biol 16(3):265-273

Thrane S, Janitzek CM, Matondo S, Resende M, GustavssonT, de Jongh WA, Clemmensen S, Roeffen W, van de Vegte Bolmer M, van Gemert GJ, Sauerwein R, Schiller JT, NielsenMA, Theander TG, Salanti A, SanderAF (2016) J Nanobiotechnol (2016)14:30

Thyagarajan R, Arunkumar N, Song W (2003) Polyvalent antigens stabilize B cell antigen receptor surface signaling microdomains. J Immunol 170(12):6099-6106

Timmerman P, Puijk WC, Boshuizen RS, Van Dijken P, Slootstra JW, Beurskens FJ, Parren PWHI, Huber A, Bachmann MF, Meloen RH (2009) Functional Reconstruction of structurally complex epitopes using CLIPSTM technology. The Open Vaccine J 2:56-67

Tissot AC, Maurer P, Nussberger J, Sabat R, Pfister T, Ignatenko S, Volk HD, Stocker H, Muller P, Jennings GT, Wagner F, Bachmann MF (2008) Effect of immunisation against angiotensin II with CYT006-AngQb on ambulatory blood pressure: a double-blind, randomised, placebo-controlled phase IIa study. Lancet 371(9615):821-827

Toapanta FR, Ross TM (2006) Complement-mediated activation of the adaptive immune responses: role of $\mathrm{C} 3 \mathrm{~d}$ in linking the innate and adaptive immunity. Immunol Res 36(13):197-210

Winblad B, Andreasen N, Minthon L, Floesser A, Imbert G, Dumortier T, Maguire RP, Blennow K, Lundmark J, Staufenbiel M, Orgogozo JM, Graf A (2012) Safety, tolerability, and antibody response of active Abeta immunotherapy with CAD106 in patients with Alzheimer's disease: randomised, double-blind, placebo-controlled, first-in-human study. Lancet Neurol 11 (7):597-604

Wyrzucki A, Bianchi M, Kohler I, Steck M, Hangartner L (2015) Heterosubtypic antibodies to influenza a virus have limited activity against cell-bound virus but are not impaired by strain-specific serum antibodies. J Virol 89.6 [Sandri-Goldin M (ed) American Society for Microbiology 3136-44] http://dx.doi.org/10.1128/JVI.03069-14 
Yang G, Holl TM, Liu Y, Li Y, Lu X, Nicely NI, Kepler TB, Alam SM, Liao HX, Cain DW, Spicer L, Vandeberg JL, Haynes BF, Kelsoe G (2013) Identification of autoantigens recognized by the 2F5 and 4E10 broadly neutralizing HIV-1 antibodies. J Exp Med 210 (2):241-256

Zakeri B, Fierer JO, Celik E, Chittock EC, Schwarz-Linek U, Moy VT, Howarth M (2012) Peptide tag forming a rapid covalent bond to a protein, through engineering a bacterial adhesin. Proc Natl Acad Sci U S A 109(12):E690-E697 